\section{The 1976-1977 Executive}

Left to right: Dan MacArthur, Chronicle Editor; A. Brookman Anderson, President; Warren Moore, Past President; Doug Redmond, 2nd-Vice-President; Art Racey, Manager. (Missing from group Paul Boucher, 1st-Vice-President.)

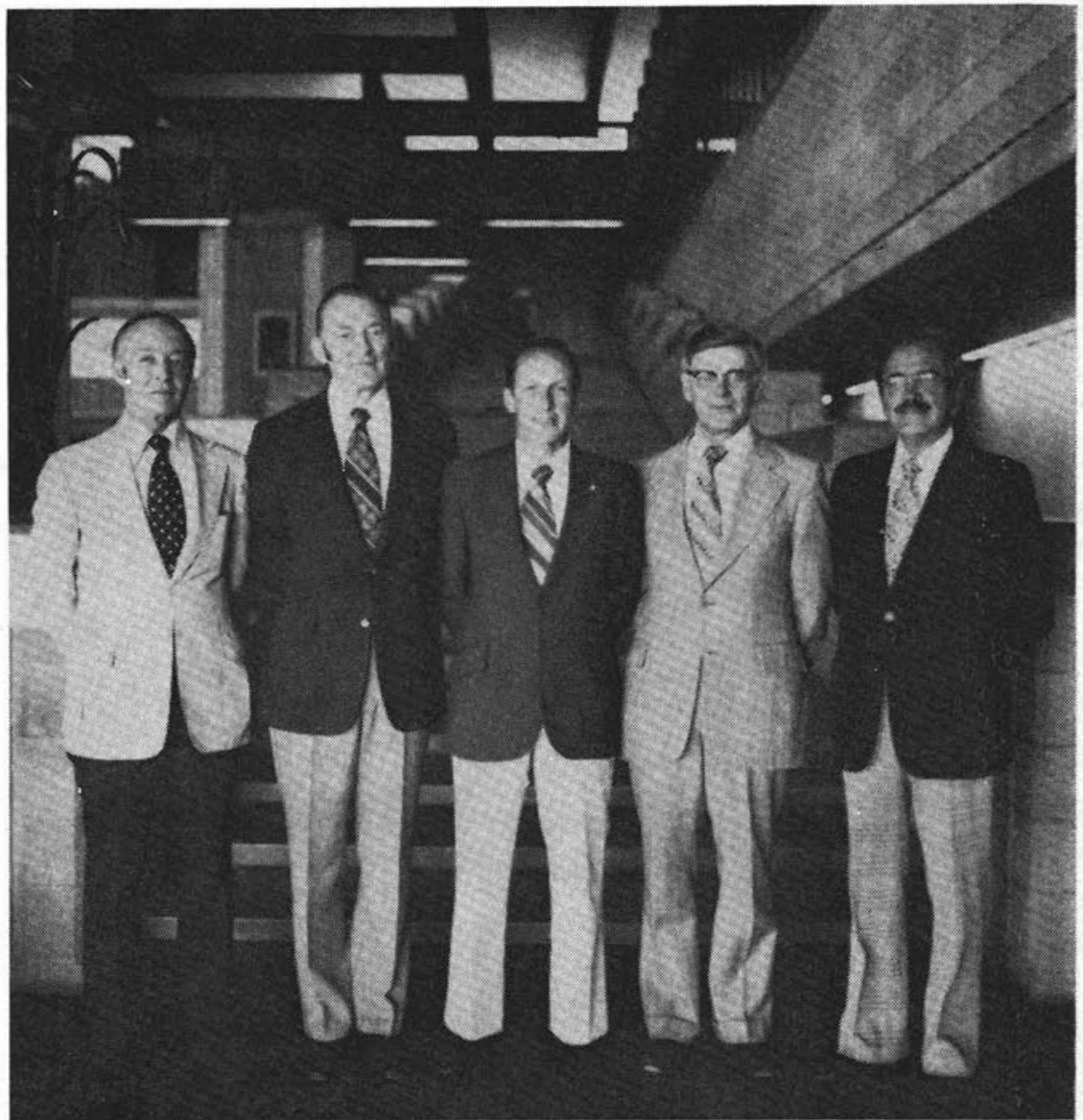

\title{
Across the Manager's Desk
}

\section{The Rules By Which We Live}

In our general everyday lives we are governed and guided by a multiplicity of laws. As they are mostly man-made, they are capable of being changed, if times change, or if a law is unenforceable, or no longer suits the needs of people, or is difficult to interpret.

As in life in general, so in the CIF. Our organization has its statutes which consist of Objectives, By-laws, Rules and Regulations and Code of ethics. When these were being drawn up, the authors took great care and attempted to cover all possible foreseeable situations that might occur. And over the years some amendments and additions have been made to fit changing times, to make administration more consistent and generally easier, and to decrease the need for interpretation wherever possible.

However, there is occasionally need for interpretation without precedent and this happened at the Annual Meeting this year.
The Algonquin Section passed a motion at their Section Annual Meeting concerning a change in the national dues rates as follows:

“Whereas, present National Dues of $\$ 45.00$ for Affiliate membership discourages forest technicians and workers from joining the Canadian Institute of Forestry;

Whereas, the present Dues for Affiliate membership differ marginally ( $\$ 5.00)$ from those for Active membership;

Resolved, that National Dues for the class of Affiliate member in the Canadian Institute of Forestry be substantially reduced from its present level to reflect the difference in privilege and responsibility between Active and Affiliate members and to encourage wider membership and communication among all concerned with forest land management.

Resolved, that dues for Affiliate membership be set at the rate of subscription to The Forestry Chronicle plus five dollars." 
This Resolution was sent to Head Office and relayed to the National Chairman of the Resolutions Committee for consideration at the National Annual Meeting. The Resolution was distributed at the Annual Meeting of the Board of Directors and there was considerable discussion.

First: the discussion revolved around the timing of submission of Resolutions and as a result recommendation was made that two amendments concerning dates be made to Rule 4.2 to ensure adequate time in the future for distribution of Resolutions to the Directors to be relayed. This recommendation was subsequently ratified by the Annual General Meeting according to procedure laid down in By-law 14. Rules and Regulations.

Second: it was agreed by the Board of Directors that all Resolutions submitted should be presented to the Annual General Meeting. However, as the Board members did not agree on the intent of the Resolution, let alone on the amount mentioned, no recommendation was made and no vote taken.

Third: based on the discussion in the Board meeting, the Algonquin Section representative discussed the Resolution with the Resolution Committee Chairman and the following was presented to the Annual General Meeting as Resolution 76.4:

Whereas present National dues of $\$ 45.00$ for Affiliate membership discourages forest technicians and workers from joining the Canadian Institute of Forestry, and

Whereas the present dues for Affiliate membership differ marginally $(\$ 5.00)$ from those for Active membership;

$B e$ it resolved that National dues for the class of Affiliate member in the Canadian Institute of Forestry be substantially reduced from its present level to reflect the difference in privilege and responsibility between Active and Affiliate members and to encourage wider membership and communication among all concerned with forest land management.

Be it further resolved that dues for Affiliate membership be set at the rate of subscription to

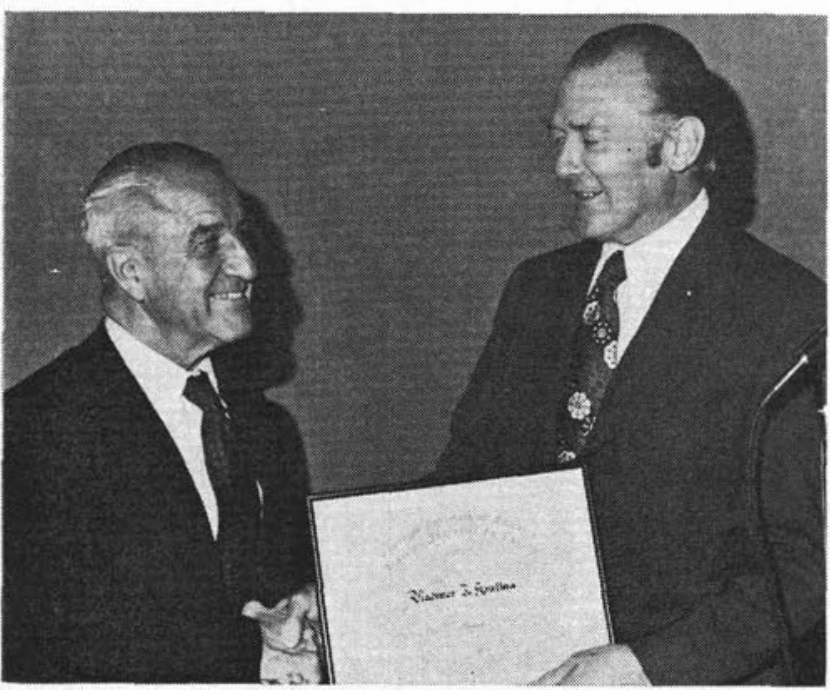

The Forestry Chronicle plus fifteen dollars (\$15.00) plus Section dues.

The motion to adopt this Resolution was carried, with five opposed.

Fourth: the President pointed out that according to By-law 14, the change in dues could not become effective until the 1978 invoicing because the Dues Schedule is part ( $R$ \& $R$ 3.1.1) of the Rules and Regulations which can only be changed by the Board of Directors. Therefore, the intent of the Resolution must be considered by the Board at its next meeting (October 1977) and its recommendation passed to the members for ratification.

Some members were not in agreement with this interpretation and have questioned me about it since. I would like to point out that there are two By-laws which back this decision and they are quoted as follows:

By-law 4.1.1 Amount and conditions of payment. The scale of membership dues and the conditions of payment may be recommended by the Board of Directors and must be ratified by vote at an annual general meeting or at any special meeting called for the purpose, inter alia, of considering the matter.

By-law 14.1 The Board of Directors may make, amend or cancel such rules and regulations as they deem fit for the proper management and operation of the Institute. Such changes of the rules and regulations must not be inconsistent with these By-laws, and shall have effect until the next annual general meeting of the Institute when they shall be ratified, repealed or amended by the membership. If ratified, with or without amendments, they shall have effect until further amended or repealed as herein described.

I would also like to point out that these by-laws are worded to make sure that matters as important as dues are not handled lightly. I would also like to point out the first paragraph in this column and repeat that laws can be amended if thought to be necessary by you, the members.

A.G. Racey

\section{Erratum}

The Forestry Chronicle, August, 1976. The statement on page 183 , column 2 , line 28 is incorrect. It should read: "significance of mountain forests in a geographic area."

Andy Anderson, newly elected President of the C.I.F., is shown here presenting the "Fellow" award to Dr. Vladimir Krajina (on the left) at the October meeting of the Vancouver Section. Dr. Krajina, Professor Emeritus from the University of B.C. was officially awarded this Fellow Member for 1976 at the recent Annual Meeting in Thunder Bay.

The Vancouver Section devoted the second meeting of the new season to Ecology and Forest Management. Prior to the regular meeting Dr. Krajina's contribution in this field was recognized followed by this presentation. 